\title{
Study on Improvement of Cold Chain Logistics Service Quality Based on QFD
}

\author{
Lipeng Wang*, Hanxing Hao \\ School of Management Engineering, Zhengzhou University, No.100 Science Avenue, Zhengzhou, China \\ 806502496@qq.com
}

Keywords: Cold chain logistics, Service quality Improvement, Quality Function Deployment

\begin{abstract}
Based on previous research, cold chain logistics service quality evaluation and improvement are the hot spots in research. The paper first introduced connotation cold chain logistics and cold chain logistics processes, the status of the cold chain logistics service quality study gives a brief introduction and summary. On the basis of analysis of the quality of the cold chain logistics formed five principles, the paper determines customer demand for quality of service through extensive research and interviews with internal and external customers for quality of service, providing a basis for the subsequent Quality Function Deployment (QFD). Finally, to make data processing more realistic and reasonable, Rough Analytical Hierarchy Process(RAHP) is adopted to calculate the weight of customer needs, and eventually calculation examples.
\end{abstract}

\section{INTRODUCTION}

Cold chain logistics as the logistics of the most dynamic industry in China's rapid adoption, showing its strong development potential, has made remarkable achievements and valuable experience, but there are also many deficiencies. In theory, the international logistics service quality management theory such as logistics service quality dimension and its composition, there are many arguments, has not yet formed a perfect system theory. China's cold chain logistics service quality research mainly draws on foreign related theories, lack of innovative research and empirical research. Most of the cold chain logistics enterprises in China lack of rationality in the formulation of competitive strategy, the same industry enterprises are often vicious price competition, rather than the quality of service competition, which has affected the satisfaction of the enterprise customers. And efficient operation of cold chain logistics enterprises. Therefore, it is urgent to study the quality of cold chain logistics service and improve the service level of our country.

Based on the analysis of relevant documents, this paper analyzes the service quality of cold chain enterprises based on the QFD model, so that enterprises have a correct understanding of the status quo of their own logistics service quality.

\section{COLD CHAIN LOGISTICS SERVICE QUALITY}

The research on logistics service quality began in the late 1970s. Until now, the research on logistics service quality can be divided into three stages: the initial stage of research, the definition of logistics service quality and the definition of some basic concepts; In the research stage of service quality components, the SERVQUAL model is the main solution, which mainly solves the problems of logistics service quality components, evaluation methods, improvement and application in management practices. In the modern research stage, the research at this stage obviously shows deepness, systematization and integration The research center moved to explore the relationship between logistics service quality and customer satisfaction, customer value, customer loyalty and business competitiveness from a strategic level.

\subsection{Logistics Service Quality Connotation}

(1) Based on the definition of logistics supplier's perspective, that is, enterprise's perspective, the most representative is $7 \mathrm{R}$ theory based on time, place and utility put forward by Perreault and Russ scholars. They think that the development of logistics service does not exist alone, but rather depends on the speed of development of the social economy. Therefore, the service process of logistics enterprises is to solve the time and space obstacles for customers in a specified time, and increase product customer value (Miroslav, 2006). With the socio-economic development, the customer has not only satisfied with the basic logistics service, but also requires the logistics service to be more rich and personalized. Therefore, the definition of the traditional logistics service based on the product operation has changed. According to this, Lalonde and Zinszer two scholars also enriched the connotation of the quality of logistics services: to meet the solution time, space obstruction at the same time to provide customers with humane value-added logistics services, that is, based on the original logistics services to create new service points and found service blueprint Market, to create a richer logistics service content, bring new profit point for the enterprise.

(2) From the perspective of customer satisfaction to define the concept of logistics service quality, mainly scholars Mentezr and others to perceive the quality of service as the theoretical framework, the logistics service is defined as not only to help customers the process of transport of goods, but to let them In the process of experiencing logistics services to enjoy a kind of spiritual enjoyment, in order to ensure the customer loyalty to the logistics business, the ultimate goal of logistics services is to continuously meet customer requirements for logistics services, and constantly 
improve the customer's economic value and corporate value. In the 21st century, American scholars, after having visited over a hundred different types of logistics enterprises, put forward the definition of the key 9 elements of logistics service quality based on the model of logistics service quality and the factors influencing the previous logistics service quality, which is greatly enriched The connotation of the quality of logistics services.

Analysis of the above research content of famous scholars, the author of the individual understanding of the connotation of the quality of logistics services are as follows:

(1) The basic quality. Basic logistics service quality refers to the basic logistics services provided by logistics enterprises to customers, including the quality of service embodied in the goods takeover, transportation and distribution and the final handover. In the process of logistics enterprises to customers for the goods at the time and place of obstruction, will meet the requirements of the product to the customer.

(2) Economic quality. When accepting basic logistics services, customers will compare the rationality of the prices of the services provided by different enterprises and the corresponding services. Therefore, enterprises should formulate reasonable pricing strategies according to market conditions and have reasonable combination of service prices and basic services. Have a higher economic quality.

(3) Innovative quality. With the rapid development of third-party logistics enterprises in contemporary society, logistics enterprises have not only provided basic logistics services but also provided personalized value-added services to customers. This is the quality of innovation. Innovative quality is a charismatic quality, these innovative services generated by the wisdom of all staff, but also for businesses to create new markets and win higher customer loyalty.

\subsection{Cold Chain Logistics Service Quality Status Quo}

(1) The status of foreign research

The SERVQUALL method of perceived quality developed by PZB, a service management research portfolio in the United States, points out that customer expectation is a precondition for quality service, and that quality of service measurement can be measured in five types of services: reliable, perceivable, reactive, guaranteed, Attribute to evaluate.

Bienstock, Mentzer, Bird proposed two aspects of logistics service quality, one is the result of the technical quality of the logistics service, and the other is the functional quality of the logistics service process. Also pointed out that the SERVQUALL scale in describing the quality of service too much emphasis on functional dimensions, then developed a new entity to verify the quality of service delivery scale.

Mentzer et al. Expanded their 1999 study (the LSQ scale) by taking the nine variables of LSQ as a process in which the components of perceived logistics service quality interacted with each other and thereby increased customer satisfaction (Bienstock, 2008).

(2) The current situation of domestic research

At present, there are not many researches on the service quality of the modern cold chain logistics in our country, mainly borrow the well-known foreign research theories, and a few scholars have their own research systems, while most of the other researches are based on foreign studies On the development of changes.

In 2013, Lu Hua and others analyzed the hazards and key control points in the cold chain logistics service process by using the method of hazard analysis and critical control point to establish the monitoring indicators. Lean $6 \sigma$ Quality management tools analyze the stability of the logistics process (Hongli, 2013).

In 2013, based on the principles of SERVQUALL and LSQ index system, Chen Hongli discussed how to establish the evaluation index system and evaluation method of fresh food cold chain logistics service quality (Hongli, 2013).

In 2015, from the perspective of product segments in the network environment, Hou Jieling made reference to the dimensionality in SERVQUALL and LSQ models and combined with the characteristics of cold chain logistics service of fresh agricultural products to construct a suitable cold chain logistics service for B2C e-commerce fresh produce Quality evaluation index system (Jieling, 2015).

In 2015, Chen Hongli and others determined the evaluation index of service quality of cold meat cold chain logistics according to the principles of independence, comprehensiveness, usability and operability, and then established the corresponding evaluation model according to FAHP, and carried out the model Instance verification (Hongli, 2015).

In 2016, Tian Xue et al. Analyzed the internal control factors and external factors affecting the quality control of cold chain logistics. Based on the analysis of the factors and characteristics of cold chain logistics quality control, the quality control framework structure of cold chain logistics was established (Xue, 2016).

In summary, the research on service quality of cold chain logistics mainly has the following problems: Firstly, a unified definition has not been formed yet for the service quality of cold chain logistics, leading to the evaluation index selected in the evaluation of cold chain logistics service quality More scattered, so far there is no unified understanding and improve the evaluation index system.Second, the research carried out by Chinese scholars focuses on the theoretical aspects, the lack of specific data analysis or just based on hypothetical data, so that the corresponding theory is not supported by empirical research, resulting in the applicability of evaluation methods to be verified. Finally, there is not a complete system of quality of service indicators for the study of different types of cold chain logistics service quality.

\section{WAY TO IMPROVE COLD CHAIN LOGISTICS SERVICE QUALITY}

\subsection{To Determine Customer Needs}

Customer demand for cold chain logistics services focus on cold chain logistics enterprises to improve customer satisfaction must understand the key aspects, it 
directly affects the quality of the function of the efficiency and advantages and disadvantages. Good customer demand Market research can not only improve the quality of the performance benefits, but also can help companies understand the market dynamics of product service adjustments. To this end, we can obtain customer' $\mathrm{s}$ logistics service demand information through market research and negotiation with customers, etc, and refine the customer needs to classify and grade, so as to establish a hierarchical customer logistics service quality requirement. In this paper, I analyze the previous research on cold chain logistics (Song, 2013). Consider the formation of the five principles of cold chain quality, through specific market research, consult the cold chain logistics scholars and university professors have come stage cold chain logistics customer service quality needs, as shown in Table 1:

Table 1 Cold chain logistics business customer service quality needs

\begin{tabular}{|c|c|c|}
\hline $\begin{array}{c}\text { first } \\
\text { level of } \\
\text { quality } \\
\text { needs }\end{array}$ & $\begin{array}{l}\text { second level } \\
\text { of quality } \\
\text { needs }\end{array}$ & third level of quality needs \\
\hline \multirow{18}{*}{$\begin{array}{l}\text { Cold } \\
\text { chain } \\
\text { logistics } \\
\text { service } \\
\text { quality }\end{array}$} & \multirow{4}{*}{ Tangible } & $\begin{array}{l}\text { The number of refrigerated trucks } \\
\text { and cold storage and technical level }\end{array}$ \\
\hline & & $\begin{array}{c}\text { Cold chain logistics process } \\
\text { standardization }\end{array}$ \\
\hline & & Rational allocation of resources \\
\hline & & $\begin{array}{l}\text { Cold chain transport price is } \\
\text { reasonable }\end{array}$ \\
\hline & \multirow{5}{*}{ Reliability } & Cold chain order fulfillment rate \\
\hline & & Cold chain cargo damage rate \\
\hline & & Customer order delivery inquiry \\
\hline & & $\begin{array}{l}\text { The ability to handle customer } \\
\text { losses }\end{array}$ \\
\hline & & Customer trust in the business \\
\hline & \multirow{3}{*}{ Responsiveness } & Cold chain order processing cycle \\
\hline & & $\begin{array}{c}\text { Timeliness of cold chain } \\
\text { transportation troubleshooting }\end{array}$ \\
\hline & & Cold chain order processing speed \\
\hline & \multirow{3}{*}{ Guarantee } & Staff professional quality level \\
\hline & & $\begin{array}{c}\text { Business and customer } \\
\text { communication level }\end{array}$ \\
\hline & & $\begin{array}{l}\text { Employees get the level of cold } \\
\text { chain support from the business }\end{array}$ \\
\hline & \multirow[t]{3}{*}{ Service } & $\begin{array}{l}\text { Provide customers with cold chain } \\
\text { logistics value-added business } \\
\text { capabilities }\end{array}$ \\
\hline & & Cold chain transport flexibility \\
\hline & & Cold chain logistics service outlets \\
\hline
\end{tabular}

\subsection{Determine the Weight of Customer Needs}

Customer demand obtained from market research during the process of quality function expansion tends to be more general, which makes the determination of customer demand fuzzy inaccurately. Analyze the previous scholars to determine the importance of customer needs in the process of developing the quality function, most of the scholars study using AHP or fuzzy comprehensive evaluation method, these methods have obvious shortcomings, not all the data are involved in the calculation process, resulting in the survey data not available Make full use of, and later developed fuzzy number AHP method to generate fuzzy analytic hierarchy process, this method compared to simple analytic hierarchy process or fuzzy comprehensive evaluation method is more realistic and reasonable. In recent years, due to its characteristics, Rough Analytic Hierarchy Process (AHP) has drawn more and more attention from scholars, while the text adopts the method of calculating the importance of customer needs based on Rough Analytic Hierarchy Process (AHP), which makes the research data processing more rigorous and objective.

Roughness analysis was proposed by Polish scholar Pawlak to process and analyze survey data. Compared with the general data analysis method, it can change the artificial judgment matrix in the AHP to construct the judgment matrix from the objective data based on the survey, which can better display the fuzziness and incompleteness of the data. The specific performance of the use of rough data processing survey, the uncertainty of the data described as a collection and collection operations.

Definition 1: Set elements of rough upper and lower approximation set. Set $U$ is the data set of our research object, usually in order to ensure the research is of practical significance, then $U$ for a finite set and not empty set, we call it the study of domain. Set $\mathrm{Y}$ is a an element in $\mathrm{R}$, the definition of the collection $R=\{C 1, C 2, \ldots C n\} \quad$ And assume $C 1<C 2<\ldots<C n$, For any one of them $C i \in R, 1 \leq i \leq n$, The rough lower approximation set of $C \mathrm{i}$ can be defined as:

$$
\underline{\operatorname{Apr}}(C i)=\bigcup\{Y \in R \mid R(Y) \leq C i\}
$$

The rough upper approximation set of $C i$ can be defined as follows:

$$
\overline{\operatorname{Apr}}(C i)=\bigcup\{Y \in R \mid R(Y) \geq C i\}
$$

The rough boundary area set of $C \mathrm{i}$ can be defined as:

$$
\begin{aligned}
& \text { Bnd }(C i)=\bigcup\{Y \in R \mid R(Y) \neq C i\} \\
& =\{Y \in R \mid R(Y)>C i\} \bigcup\{Y \in R \mid R(Y)<C i\}
\end{aligned}
$$

The definition 1 through the collection and collection boundaries to characterize the entire collection of data features. Assumptions $C \mathrm{i}$ Is a elements of collection R, its rough lower approximate set depends on the element value in collection $\mathrm{R}$ that is less than or equal to $\mathrm{Ci}$; and the rough upper approximation set depends on the element value in collection $\mathrm{R}$ that is greater than or equal to $\mathrm{Ci}$;The rough boundary area set of $\mathrm{Ci}$ Consists of the element that is not equal to $\mathrm{Ci}$.

Define 2: Rough numbers and rough boundary intervals of the elements. From the above description, study on elements $C \mathrm{i}$ which is in the collection, the characteristics of an ambiguous partition can be expressed by the number of rough, its rough number by the upper limit of roughness $(\overline{\operatorname{Lim}}(\mathrm{Ci}))$ and the lower limit of roughness $\operatorname{Lim}(\mathrm{Ci})$ ) , The rough upper and lower mathematical expressions can be expressed as:

$$
\underline{\operatorname{Lim}}(\mathrm{Ci})=1 / M L \sum R(Y) \mid Y \in \operatorname{Apr}(C \mathrm{i})
$$


Among them $M L$ is the number of set elements contained in the rough lower approximation set.

$$
\overline{\operatorname{Lim}}(C \mathrm{i})=1 / M U \sum R(Y) \mid Y \in \operatorname{Apr}(C \mathrm{i})
$$

Among them $M U$ is $C \mathrm{i}$ the number of set elements in rough upper approximation set.

Rough boundary interval is $\operatorname{RBnd}(\mathrm{Ci})$, The mathematical expression is:

$$
\operatorname{RBnd}(C \mathrm{i})=\overline{\operatorname{Lim}}(C \mathrm{i})-\underline{\operatorname{Lim}}(C \mathrm{i})
$$

Through the above definition and the application of mathematical formulas, we conclude that the ambiguity partition in the data set of the research object can be represented by rough numbers and average rough intervals. The specific mathematical formula is:

$$
R N(C i)=[\overline{\operatorname{Lim}}(C \mathrm{i}), \underline{\operatorname{Lim}}(C \mathrm{i})]
$$

To sum up, by calculating the rough set and average rough interval divided by set data, the uncertainty of the data can be characterized. The larger the average rough interval is, the higher the data set fuzziness is. Compared with fuzzy analytic hierarchy process (AHP), which uses fixed fuzzy interval to characterize data objects, it is very flexible to use rough numbers and average rough intervals to better reflect the general needs assessment which is not easy to quantify. At the same time, we can see from the definitions of rough numbers and average rough intervals that all the data of the data set are involved in the process of calculating the rough numbers of data. Since the data is obtained according to the specific market survey, the data are represented by rough numbers and rough intervals. All the data involved in the evaluation is the overall cognition of all customer service quality requirements in the survey, which makes the final result of data processing more authentic and objectivity.

Step 1: Finishing customer needs through market research and sorting, and refinement of customer needs for classification, grading, so as to establish a hierarchical customer needs. As shown in Table 3-1.

Step 2 Investigate the opinions of the professors and school professors related to the cold chain logistics, make the AHP questionnaire of customer needs, and obtain the paired comparison matrix among customer needs. There are $s$ experts and professors participated in the survey, we will investigate $s$ analyze the AHP questionnaire into customer demand comparison matrix as follows:

$$
A_{i}=\left[\begin{array}{cccc}
1 & X_{12}^{\mathrm{i}} & \ldots & X_{1 \mathrm{~m}}^{\mathrm{i}} \\
X_{21}^{\mathrm{i}} & 1 & \ldots & X_{2 \mathrm{~m}}^{\mathrm{i}} \\
\cdots & \ldots & 1 & \cdots \\
X_{\mathrm{n} 1}^{\mathrm{i}} & X_{\mathrm{n} 2}^{\mathrm{i}} & \ldots & 1
\end{array}\right],
$$

among them $i \in[1, s]$.

In order to ensure the rationality of the data processing process, survey the $\mathrm{s}$ pair of comparison matrix, and do consistency test. Use equations $C I=\left(\lambda_{\max }-n\right) /(n-1)$, we can get consistency index $C I$ in matrix $A$.In the equation: $\lambda_{\max }$ is the maximum eigenvaluea in matrix $A$ which can be calculated by using Matlab, $\mathrm{n}$ is the ordera of matrix $A$. Now it is more reasonable to compare the consistency of the matrix by the consistency ratio $C R$, among them $C R=C I / R I . R I$ is the randomness index of the matrix. If $C R<0.1$, That the contrast matrix judgment is consistent, if $C R \geq 0.1$, Then the comparison matrix needs to be transformed, until $C R<0.1$.

Step 3: Consolidate the customer requirement comparison matrix that passed the consistency test in Step 2, it mean that put together the same customer demand to form a set of elements. The resulting matrix is called a rough group decision matrix. Roughness and average roughness of each element in the set of elements of the matrix can be obtained through equations (1) - (7) . The specific calculation process is:

Consolidate customer demand comparison matrix to get rough group decision matrix:

$$
A^{*}=\left[\begin{array}{cccc}
1 & x_{12}^{*} & \ldots & x_{1 m}^{*} \\
x_{21}^{*} & 1 & \ldots & x_{2 m}^{*} \\
\ldots & \ldots & 1 & \ldots \\
x_{n 1}^{*} & x_{n 2}^{*} & \ldots & 1
\end{array}\right],
$$

among them $x_{12}^{*}=\left\{x_{12}^{1}, x_{12}^{2}, \ldots, x_{12}^{s}\right\}$.

According to the algorithm of rough numbers, it is easy to get the average roughness range of set of elements $x_{12}^{*}$ in the rough group decision matrix:

$$
\begin{gathered}
R N\left(x_{12}^{*}\right)=\left\{\left(x_{12}^{1-}, x_{12}^{1+}\right),\left(x_{12}^{2-}, x_{12}^{2+}\right), \ldots,\left(x_{12}^{s-}, x_{12}^{s+}\right)\right\} \\
x_{12}^{+}=\left(x_{12}^{1+}+x_{12}^{2+}+\ldots+x_{12}^{s+}\right) / s \\
x_{12}^{-}=\left(x_{12}^{1-}+x_{12}^{2-}+\ldots+x_{12}^{s-}\right) / s
\end{gathered}
$$

Using the same method, we can find the average roughness of all the elements in the set among the rough group decision matrix $A^{*}$.

Step 4: Constructs a rough pairwise comparison matrix based on the rough numbers and average rough intervals calculated in Step 3. The matrix consisting of the average rough interval is called the rough pairwise comparison matrix of customer needs.

$$
X=\left[\begin{array}{cccc}
(1,1) & \left(x_{12}^{-}, x_{12}^{+}\right) & \ldots & \left(x_{1 n}^{-}, x_{1 n}^{+}\right) \\
\left(x_{21}^{-}, x_{21}^{+}\right) & (1,1) & \ldots & \left(x_{2 n}^{-}, x_{2 n}^{+}\right) \\
\ldots & \ldots & (1,1) & \ldots \\
\left(x_{n 1}^{-}, x_{n 1}^{+}\right) & \left(x_{n 2}^{-}, x_{n 2}^{+}\right) & \ldots & (1,1)
\end{array}\right]
$$

among them, $n$ is customer demand quantity.

Step 5: According to the above results to calculate the current level of customer needs weight. Decomposi the rough pairwise comparison matrix $X$. Consists by the lower limit of the average rough interval as a matrix element matrix $X^{-}$which is known as the rough lower boundary matrix, the same reason consists by the average rough interval upper limit as a matrix element matrix $X^{+}$which is known as the rough upper bound matrix. Using the matrix eigenvalue calculation 
command in Matlab software to calculate the corresponding maximum eigenvalue and eigenvector for the rough upper and lower boundary matrices respectively, the eigenvectors are normalized according to the obtained eigenvectors, and finally the weight of customer needs is obtained. The specific calculation process is as follows: $X$ :

Decomposition Rough Pairwise Comparison Matrix

$$
\begin{aligned}
X^{-} & =\left[\begin{array}{cccc}
1 & x_{12}^{-} & \ldots & x_{1 m}^{-} \\
x_{21}^{-} & 1 & \ldots & x_{2 m}^{-} \\
\ldots & \ldots & 1 & \ldots \\
x_{n 1}^{-} & x_{n 2}^{-} & \ldots & 1
\end{array}\right] \\
X^{+} & =\left[\begin{array}{cccc}
1 & x_{12}^{+} & \ldots & x_{1 m}^{+} \\
x_{21}^{+} & 1 & \ldots & x_{2 m}^{+} \\
\ldots & \ldots & 1 & \ldots \\
x_{n 1}^{+} & x_{n 2}^{+} & \ldots & 1
\end{array}\right]
\end{aligned}
$$

The corresponding maximum eigenvalues and eigenvectors are:

$$
W_{i}^{+}=\left\lfloor w_{1}^{+} w_{2}^{+} \ldots w_{n}^{+}\right\rfloor, W_{i}^{-}=\left[w_{1}^{-} w_{2}^{-} \ldots w_{n}^{-}\right]
$$

The basic importance of customer needs is:

$$
W_{i}=\left(\left|W_{i}^{-}\right|+\left|W_{i}^{+}\right|\right) / 2
$$

Among them

$$
\begin{gathered}
W_{i}^{-}=w_{i}^{-} / \sum_{i}^{n} w_{i}^{-} \\
W_{i}^{+}=w_{i}^{+} / \sum_{i}^{n} w_{i}^{+}
\end{gathered}
$$

Step 6: Integrated calculation of customer demand total importance. In step 5, the calculated customer demand weights at various levels are integrated, and the importance of customer needs in the parent level is multiplied by the importance of customer needs in the sub-levels. The final calculation result is the total importance of the basic customer requirements degree. which is:

$$
W_{i}^{*}=W_{1 i} \times W_{2 i} \times \ldots \times W_{m i}
$$

among them, $W_{i}^{*}$ is the after expansion importance of the basic customer's demand, $W_{1 i}$ is the weight that the $\mathrm{i}$ th basis customer demand among the first level of customer demand, $W_{2 i}$ is the weight that the $\mathrm{i}$ - th basis customer demand among the second level of customer demand, $\mathrm{m}$ is the level of customer demand.

\subsection{To Determine the Key Customer Service Quality Needs}

Through market research, we analyze the satisfaction of benchmarking enterprises and enterprises in the industry for the quality of customer service that has been constructed. According to the satisfaction of benchmarking enterprises to determine the appropriate customer service quality needs improvement goals, combined with the company's own situation to determine the level of improvement. Calculate the rate of improvement and the weight of customer needs, and determine the key customer service quality requirements through the calculation results. In the table, the improvement rate is equal to the ratio of the improvement level to the Company's satisfaction level in comparative analysis. The absolute weight is equal to the product of importance and improvement rate of customer service quality. The relative weight is the result of normalization of absolute weight. The relative importance of service quality requirements between the evaluation.

\subsection{Cold Chain Logistics Service Quality Improvement}

Invited cold chain logistics experts, university professors, employees and business managers to conduct a forum. By analyzing the elements of service resources of cold chain logistics enterprises that affect customer service quality requirements, the author finally selected cold chain logistics infrastructure and cold chain logistics process operations Standard, internal management processes, the professional quality of employees, the construction of enterprise cold chain logistics information system, value-added services such as business enterprises six cold chain logistics service resources as an improvement object. According to the relation matrix, according to the close relationship between the key customer logistics service quality requirements and cold chain logistics enterprise service resource elements, cold chain logistics experts and university professors subjectively scored according to social industry status quo and research experience, from weak to strong to express.

$$
G_{i}=\sum_{1}^{n} W_{i} r_{i j}
$$

In the equation, $i$ on behalf of the basic customer service quality needs, $j$ on behalf of cold chain logistics business service resources, $n$ Represents the number of basic customer service quality requirements, $r_{i j}$ is the relation matrix $i$ row $j$ the value of the column element, $W_{i}$ is the total customer service quality needs of the total importance. The relationship matrix is:

$$
R_{i}=\left[\begin{array}{cccc}
r_{11} & r_{12} & \ldots & r_{1 m} \\
r_{21} & r_{22} & \ldots & r_{2 m} \\
\ldots & \ldots & \ldots & \ldots \\
r_{n 1} & r_{n 2} & \ldots & r_{n m}
\end{array}\right]
$$

According to the above steps to carry out the service quality function, cold chain logistics enterprises can get the key customer service quality requirements and the key enterprise service resource elements at this stage, 
which is the focus of attention when the cold chain logistics enterprises conduct service quality management. Should be based on the reality of enterprises and industries, development of service quality improvement strategy. Specifically, prioritizing weight rankings improves service resource elements with lower difficulty scores, giving priority to the use of enterprise resources for improvement, and developing clear standards for standardizing cold-chain processes so as to achieve the highest quality of service improvement benefits with minimal resource costs.

\section{CONCLUSIONS}

Due to the unique cold chain, cold chain logistics services, the complexity. It is difficult to manage and control the service quality of cold chain logistics enterprises, leading to the low quality of service enterprises in China cold chain logistics is generally low. So this paper summed up the status of China's cold chain logistics enterprises. Analyze the problems and shortcomings of Chinese enterprises by comparing the development of international cold chain logistics. Finally, QFD method is used to improve the quality of cold chain logistics service. In this paper, rough AHP is used to improve the shortcomings of using AHP.Sort the weight of the customer's needs. Use the quality function to start from the enterprise service resources elements to find key ways to improve. This paper discusses the basic problems of the analysis and improvement of the service quality of the third party cold chain logistics enterprises, and puts forward the improvement ideas of the cold chain logistics enterprises for the service quality problems.

\section{REFERENCES}

[1] Miroslav, V., 2006. Discussing the parameters of preservation of perishable goods in a cold logistic chain model, Applied Economics. 38(2), pp.137-147.

[2] Bienstock, C., Royne, M., Dan, S., et al., 2008. An expanded model of logistics service quality: Incorporating logistics information technology, International Journal of Production Economics. 113(1), pp.205-222.

[3] Hongli, C., Hua, L., 2013. Quality Evaluation of Cold Chain Logistics Service Process, China's circulation economy. 27(1), pp.34-39.

[4] Hongli, C., Jinying, L., Jiaming, R., 2013. How to Establish the Index System of Service Quality Evaluation of Fresh Food Cold Chain Logistics, Logistics Technology. 36(7), pp.20-22.

[5] Jieling, H., Ling, L., 2015. Study on B2C e - commerce Fresh Food Cold Chain Logistics Service Quality Evaluation, Logistics Technology. 38(6), pp.132-135.

[6] Hongli, C., Liyao, Z., Xin, Z.,2015. FAHP - based Fresh Food Cold Chain Logistics Service Quality Evaluation Model Construction, Logistics Technology. 34(7), pp.142-145.

[7] Xue, T., Cai, Y., 2016. Study on Cold Chain Logistics Service Quality of Fresh Products, China's storage and transportation. (2), pp.115-117.

[8] Song, Z., 2013. Analysis of the Current Status of Cold Chain Logistics in China, Manage observations. (18), pp.58-60.

[9] Ni, Z., Tao, Y., 2012. Research on the Construction and Evaluation of Logistics Service Quality Indicators, Logistics Technology. 31(10), pp.140-143.

[10] Xiaotun, W., Wei, X., Rough Analytic Hierarchy Process for Determining Importance of Customer Needs in Quality Function Deployment, Computer Integrated Manufacturing System. 16(4), pp.763-771. 